\title{
Halk Sağlığında Yapay Zekanın Kullanımı
}

\author{
Halit Emin ALICILAR, Meltem ÇÖL \\ Ankara Üniversitesi Tıp Fakültesi, Halk Sağlığı Anabilim Dalı, Ankara.
}

\begin{abstract}
ÖZET
Teknolojik gelişmelerin sağlık sektörüne her geçen gün daha fazla dahil olmasıyla tıp alanında yapay zekaya verilen önem de giderek artmaktadır. Son dönemde yaşanan gelişmeler tüm alanlarda olduğu gibi Halk Sağlığında da umut ve heyecan vericidir. Geleceğe yönelik olarak yapay zekanın uygulama olanakları ve özellikle büyük verinin potansiyeli oldukça büyüktür. Halk Sağlığında yapay zeka uygulamaları için sürveyans sistemleri, epidemiyolojik analizler, sağlık risklerinin saptanması, hastalıkların erken tanısı, salgın yönetimi ve aşı çalışmaları gibi birçok kullanım alanı bulunmaktadır. Bunun yanında yapay zekanın modern tıbba entegre edilmesinin bazı potansiyel olumsuz sonuçları da mevcuttur. Bu derlemenin amacı, yapay zeka kavramı hakkında bilgi vererek çeşitli uygulama örnekleri üzerinden Halk Sağlığında yapay zekanın kullanım alanlarını, potansiyel faydalarını ve geliştirilmesi gereken yönlerini değerlendirmektir.
\end{abstract}

Anahtar Kelimeler: Halk Sağlı̆̆ı. Yapay zeka. Büyük veri.

Usage of Artificial Intelligence in Public Health

\begin{abstract}
With the increasing inclusion of technological developments in the health sector, the importance given to artificial intelligence in the field of medicine is increasing. Recent developments are hopeful and exciting in Public Health as in all fields. For the future, the application possibilities of artificial intelligence and especially the potential of big data are quite high. There are many uses for artificial intelligence applications in Public Health such as surveillance systems, epidemiological analysis, determination of health risks, early diagnosis of diseases, epidemic management and vaccine studies. Besides, there are some potential negative consequences of integrating artificial intelligence into modern medicine. The aim of this review is to give information about the concept of artificial intelligence, and to evaluate the uses, potential benefits and aspects that need improvement of artificial intelligence in Public Health through various application examples.
\end{abstract}

Key Words: Public Health. Artificial intelligence. Big data.

Teknolojik gelişmeler sağlık sektörüne her geçen gün daha fazla dahil olmaktadır. Günümüzde hekimlerin rutin uygulamalarında yer alan tıbbi aletlerin yanı sira bilgi yönetim sistemleri gibi birçok araç teknolojinin ürünü olarak gelişmiştir. Hekimlerin büyük çoğunluğu artık bilimsel literatüre dijital ortamdan ulaşmaktadır. Karar verme sürecinde sıklıkla teknolojiden yararlanılmaktadır.

Geliş Tarihi: 05.Mart.2021

Kabul Tarihi: 08.Nisan.2021

Dr. Halit Emin ALICILAR

Ankara Üniversitesi Tıp Fakültesi,

Halk Sağlığı Anabilim Dalı,

Ankara Tıp Cebeci Hastanesi

Balkiraz Mahallesi, Tıp Fakültesi Caddesi,

Mamak, ANKARA.

Tel: 05345112208

E-posta: eminalicilar@gmail.com
Yapay zeka (artificial intelligence), makine öğrenimi (machine learning) ve derin öğrenme (deep learning) teknolojilerinin bütün sektörlerde olduğu gibi tıp alanında da kullanımı giderek artmaktadır. Tıp alanında yapay zeka uygulamaları sıklıkla klinisyenler için radyolojik görüntülerin hızlı ve doğru biçimde yorumlanması amacıyla kullanılırken sağlık sistemleri için iş akışını hızlandırmak ve hataları en aza indirmek amaçlanmaktadır. Aynı zamanda büyük verinin (big data) işlenerek sağlığın geliştirmesi en önemli amaçlardan biridir. Gelecekte tüm sağlık çalışanlarının yapay zeka teknolojilerini kullanacağı ve bu teknolojilerin insan zekasıyla birleştirilerek "yüksek performanslı tıp" alanının oluşacağına dair görüşler mevcuttur ${ }^{1}$. Bu derlemenin amacı, yapay zeka kavramı hakkında bilgi vererek çeşitli uygulama örnekleri üzerinden Halk Sağlığında yapay zekanın kullanım alanlarını, potansiyel faydalarını ve geliştirilmesi gereken yönlerini değerlendirmektir. 


\section{Yapay Zeka Kavramı}

Zeka, Türk Dil Kurumu tarafindan "insanın gerçekleri algılama, akıl yürütme ve sonuç çıkarma yeteneği" olarak tanımlanmışır². Yapay zeka, "doğal" olan bu insan zekasına alternatif olarak makine tarafindan geliştirilen zekanın adıdır. Makinenin insana benzer biçimde, çevresini algılayarak elde ettiği bilgileri analiz edip sonuca varma yeteneği yapay zeka olarak adlandırılmaktadır ${ }^{3}$. İnsan zekası eğitimle ve deneyimlerle gelişirken makineler de uygun "eğitim" ve yeterli "deneyim” sayesinde zekaya sahip olabilmektedir.

Algoritma, bir sorunu çözmede izlenecek adımları tanımlar. Yapay zeka basit koşullu ifadeler üzerine kurulu karmaşık algoritmalardan oluşmaktadır. Basit bir algoritmada makineye bir 'a' koşulu tanımlanarak ilgili koşul gerçekleștiğinde ve gerçekleșmediğinde ne yapacağı gibi adımlar tek tek tanımlanır. Makine öğrenimi ise yapay zekanın bir alt kümesi olup algoritmaların ve modellerin sonucu olarak üretilen kalıplara ve çıkarımlara dayanır ${ }^{4}$. Burada tüm algoritmalar yazılıme tarafindan tek tek yazılmaz. Bunun yerine makineye örnek veriler ve çıkarımlardan oluşan bir "eğitim" seti öğretilir ve model oluşturularak makinenin tahminler yapması sağlanır. Makine öğreniminin bir ileri aşaması olan derin öğrenmede ise sinir sistemine benzer bir öğrenme amaçlanır ${ }^{5}$. Makineye katmanlar şeklinde bilgiler öğretilerek, bilgilerin ilişkilerini analiz etmesi ve ileri durumlarda kendi algoritmasını oluşturması sağlanır. Bu sayede yazılımcının tanımlamadığı durumlarda dahi makine kendi çözümünü üretir. Derin öğrenme sayesinde yüz tanıma, ses tanıma, tıbbi görüntü analizi gibi sonuçlar elde etmek mümkündür.

Yapay zeka, bu tanımlardan anlaşılacağı üzere çok gelişmiş öğrenme yeteneğine sahip olup karmaşık verilerin otomatik olarak çıkarılması ve analizi yoluyla açıkça kodlamaya gerek kalmadan bilgisayarın öğrenmesini sağlar ${ }^{6}$. Bilgisayar hatalarından adeta ders çıkarır ve sürekli gelișir. Üstelik uygun veriler sağlandığı taktirde edindiği yeni bilgileri test etme, başarı oranını kendi kendine takip etme ve gerekirse öğrendiği bilgiyi unutarak kendini düzeltme yeteneğine de erişebilir.

Yapay zekanın tıpta kullanımı ile ilgili en büyük tereddütler, karar verme aşamasını hekimden alacağı ve bu aşamada insanın yerini tutamayacağı yönündedir. Ancak diğer teknolojik gelişmelerde olduğu gibi yapay zekanın da amacı hekimin yerine karar vermek değil hekime karar verme sürecinde destek olmaktır?

\section{Tıp Alanında Yapay Zeka Uygulamaları}

Son 10 yılda, tıp alanında yapay zekayla ilgili yayınların sayısı bir hayli artmıştır. Günümüzde depolama imkanlarının ucuzlaması ve işleme gücünün artmasıyla bilgisayarlar bir hekimin ömrü boyunca edinebileceği deneyime birkaç saniyede erişebilme imkanına sahip hale gelmiştir.

Meme taraması yapay zekanın radyolojik görüntülemedeki başlica uygulamalarından biridir. Memenin yoğun dokusu nedeniyle, mamogram sonuçları üzerine hazırlanan radyoloji raporları değişkenlik gösterebilmekte ve sıklıkla görüntülerin tekrar değerlendirilmesini gerektirmektedir ${ }^{8}$. Lezyon sinıflandırmasında kullanılan yapay zeka uygulamaları; bir tümör ile normal dokuyu, malign ile benign lezyonları ayırt etme aşamasında pikseller üzerinden tahmin yürütmeye dayanmaktadır. Görüntü işleme yöntemiyle hangi piksellerin ilgili yapının normal parçaları olduğu, hangi piksellerin ise anormal olduğu belirlenir.

Meme görüntülemesi dışında yine radyolojik olarak akut iskemik görüntülemede otomatik analiz algoritmaları kullanan sistemler mevcuttur ${ }^{9}$. Bu sistemler bilgisayarlı tomografi ve manyetik rezonans görüntüleme verilerini bir arada değerlendirerek tromboembolik vasküler oklüzyonları, enfarktüs çekirdeğini ve risk altındaki potansiyel enfarktüs dokularını tespit etmede yardımcı olmaktadır. Yine bir görüntüleme uygulamaS1 olarak glokom tanısında da yapay zekanın \%96 başarı oranıyla kullanımına örnekler mevcuttur ${ }^{10}$.

Khorrami ve ekibi, küçük hücreli dışı akciğer kanseri hastalarının immünoterapiye yanıtlarını kestirebilmek için yapay zeka uygulamalarından yararlanmak üzere bir çalışma yapmıştır ${ }^{11}$. Retrospektif olarak mevcut hasta verileri üzerinden yapılan analizde, makine öğrenimi ile tedavinin 2-3 küründen önce ve sonra tümör nodüllerinin Bilgisayarlı Tomografi modellerindeki değişiklikler karşılaştırılmıştır. Sonuçlar sistemin tedavinin erken dönemlerinde hastaların yanıtlarını tanımlayabilmek için kullanılabileceği yönündedir.

Tütün ve ark. tarafindan geliştirilen WeCureX projesi danışanların sorulara vermiş olduğu cevaplar üzerinden mental bozuklukların analizi ve teşhisini amaçlayan bir yapay zeka asistanı uygulamasidır ${ }^{12}$. Uygulama hastaların psikometrik verileri ile hastalara konulan tanılar ve değerlendirmeler üzerinden eğitilerek oluşturulmuştur. Çalışmada yapay zeka asistanının elde ettiği veriler üzerinden \%97 tutarlılıkla tanıya ulaşabildiği bildirilmiştir.

Alzheimer tanısında kişilerin dijital ekran üzerinden saat çizmesi ve çizimlerin yapay zeka ile değerlendirilmesi sonucu \%80'in üzerinde başarılı tanı koyabilen bir mobil sistem geliştirilmiştir ${ }^{13}$. Dermatologlarla nevüslere tanı koymak üzere yarışan ve oldukça başarılı olan yapay zeka asistanlarıyla ilgili çalışmalar mevcuttur ${ }^{14}$. Geriatrik hastaların ilaç saatlerini hatırlatan sistemler, yüz imgeleri üzerinden Down sendromu tespiti, konuşmaları metne dökerek semantik analiz yöntemiyle psikiyatrik tanı koyma gibi birçok alanda daha yapay zeka uygulamaları geliştirilmektedir. Tüm bunlar tıp alanında yapay zeka uygulamalarına verile- 
bilen umut verici örneklerden yalnızca birkaçı olup bunun dışında genetik araştırmalar, ilaç çalışmaları ve antibiyotik direnci gibi konularda da önemli katkılar sunmaktadır.

\section{Halk Sağlığı Alanında Yapay Zeka Uygulamaları}

Halk Sağlığında yapay zeka uygulamalarının birçok kullanım alanı bulunmaktadır. Sürveyans sistemleri, epidemiyolojik analizler, sağlık risklerinin saptanması, hastalıkların erken tanısı, salgın yönetimi ve aşı çalışmaları gibi konular kullanım alanlarına örnek verilebilir.

\section{Büyük Veri}

Halk Sağlığı alanında sıklıkla "büyük veri” kavramı üzerine yoğunlaşılmaktadır. Büyük veri, geleneksel analiz yöntemleriyle işlenemeyen büyük miktarda bilginin varlığını tanımlar ${ }^{15}$. Son yıllardaki teknik ve dijital gelişmeler, veri miktarında benzersiz bir artış sağlamıştır. Günümüzde ulaşılan depolama kapasiteleriyle bağlantılı olarak, muazzam potansiyele sahip veri dağlarıyla karşı karşıyayız. Bu derece yüksek boyutlu ve karmaşık verileri değerlendirmek için bilgisayar destekli modeller ve makine öğrenim süreçleri gereklidir. Büyük verinin değerlendirilmesi zor olduğu kadar sonuçları da aynı ölçüde değerlidir.

Değişen veri dünyasında verilerin kapsayıcı, eksiksiz, sürekli ve değerlendirilebilir olması büyük önem taşır. $\mathrm{Bu}$ temeller üzerine kurulacak sistemlerle ulusal ölçekte, hatta uluslararası düzeyde sağlık kayıtları bir arada tutularak, Dünya çapında hastalıkların epidemiyolojisi takip edilebilir. Makine öğrenimi sayesinde daha önce insan zekasıyla fark edilmeyen yeni ilişkiler ortaya konabilir, yeni etiyolojiler keşfedilebilir. Toplumun tamamının tıbbi geçmişi incelenerek gelecekte karşılaşabilecek sağlık risklerinin öngörülmesi mümkün olacaktır ${ }^{16}$.

İleri bir yaklaşımla, elde edilen büyük miktarda veri, hastalıkların yeniden sınıflandırılmasını, biyolojik ve psikososyal alt tiplerin oluşturulmasını sağlama potansiyeline sahiptir. Miotto ve ark. 2015 yılında New York'ta bir hastane sistemi üzerinde yaptıkları çalışmada 700.000 hastanın verisini işleyerek Derin Hasta (Deep Patient) adını verdikleri bir sistem geliştirmişlerdir ${ }^{17}$. Derin Hasta sistemi, bireylerin çeşitli hastallkları geliştirme olasılıklarını değerlendirerek gelecekteki sağlık durumlarını öngörmeye çalışmaktadır. 6 aylık kisa bir izlem periyodunda dahi \%40'lara varan başarı yakalayan sistemin en yüksek performansları özellikle diyabet ve çeşitli kanserler için gösterdiği belirlenmiştir. Bu bulgular, yapay zeka ve derin öğrenmenin, gelişmiş klinik tahminler sunmak ve hastalikları meydana gelmeden tahmin etmek için önemli bir çerçeve sunması adına umut vericidir.
Günümüzde halka açık birçok biyolojik veri tabanı bulunmaktadır. Kanserli hastaların ayrıntılı bilgilerini içeren Kanser Genomu Atlası (The Cancer Genome Atlas) ve onaylanmış, araştırma aşamasında olan ve hatta geri çekilen ilaçları barındıran DrugBank gibi birçok örnek verilebilir ${ }^{18}$. Büyük veri tabanlarının yapay zeka ile işlenmesi ilaç keşiflerinin ilerlemesinde de önemli bir rol oynamaktadır. Exscientia adlı bir İngiliz şirketi ve Sumitomo Dainippon Pharma adlı Japon ilaç firmasının ortaklığında Obsesif Kompulsif Bozukluk hastaları için geliştirilen ilaç, yapay zeka ile geliştirilen ilk ilaç olma özelliğini kazanmıştır ${ }^{19}$. Bu ilacın klinik deneme aşamasına geçmesi yalnızca 12 ay sürmüştür.

Gönel ve ark. Şanlıurfa'da bir hastanede yaptıkları çalışmada yapay zeka programıyla gereksiz laboratuvar istemlerinin önüne geçmeyi başarmıştır ${ }^{20}$. Hastane bilgi yönetim sisteminden istemi yapılan AST, direkt bilirubin gibi testlerin gereksiz istemlerinin önüne geçmek üzere geliştirdikleri 5 algoritma ile yaklaşık 2 y1lda 600 binin üzerinde gereksiz testi önlemişlerdir. Çalışmada algoritmaların ülke genelinde tüm devlet hastanelerinde uygulanması halinde yıllık 200 milyon liralık tasarrufun mümkün olduğu bildirilmiştir.

\section{Bulaşıcı Hastalıklar}

ABD'de Lu ve ark. internet tabanlı verileri kullanarak resmi raporlar öncesinde bulaşıcı hastalık aktivitesini tahmin edebilecek bir sistem üzerine çalışma yapmış$\mathrm{tır}^{21}$. Bu çalışmada influenza salgını döneminde influenza hakkındaki Google arama sıklıklarını, elektronik sağlık kayıtlarından gelen bilgileri ve her eyaletteki geçmiş grip eğilimlerini birleştiren, kendi kendini düzelten bir istatistiksel yöntem kullanılmış ve başarılı olunmuştur. $\mathrm{Bu}$ yaklaşım sayesinde hedefe yönelik, zamanında ve nüfusa özgü müdahaleler sağlanması amaçlanmıştır.

Yine bir salgın yaklaşımı olarak Kanada'da kuş gribi salgınını gerçek zamanlı ve otomatik olarak izlemek için Twitter tabanlı bir veri analizi sistemi geliştirilmiştir ${ }^{22}$. Temmuz 2017'den Kasım 2018'e kadar Twitter'da kuş gribini tartışan, birçok ülkeden 209.000'den fazla gönderi toplanıp analiz edilerek resmi raporlarla karşılaştırılmış ve verilerin salgını temsil etme potansiyeli incelenmiştir. Yapay zeka, Twitter üzerinden gerçek dünyadaki salgın bildirimlerinin \%75'ini başarıyla tanımlayabilmiştir. Üstelik bu bildirimlerin üçte biri gerçek raporlardan da önce saptanmıştır. Benzer sistemlerin kurulmasıyla geleneksel sürveyans sistemlerinin güçlendirilmesi ve salgınların erken dönemde tespiti sağlanabilecektir.

Gonzalez ve ark. iklim değişikliğine bağlı olarak vektörlerin yaşam alanlarındaki değişikliklerin tahmin edilmesi üzerine bir çalışma yayınlamıştır ${ }^{23}$. Yazarlar bir dizi ekolojik model oluşturarak kum sineği vektör türlerinin coğrafi olarak nasıl yer değiştirebileceğini tahmin etmek için bir algoritma kullanmışlardır. Elde 
edilen sonuçlara dayanarak, iklim değişikliğinin $\mathrm{Ku}-$ zey Amerika ve Meksika'nın kuzeyinde leişmanyazisin yayılma şansını artıracağı ileri sürülmüştür.

\section{COVID-19}

2019 yılının sonunda başlayıp hala devam etmekte olan COVID-19 pandemisinde yapay zeka teknolojileri daha çok gündeme gelmeye başlamıştır. Yapay zeka erken tanı koyma, hastalık yayılımını izleme, temasl1ları takip etme, risk altındaki kişileri belirleme ve gelecek için projeksiyonlarda bulunma gibi potansiyel faydalara sahiptir ${ }^{24}$. Ayrıca virüs yapısını belirlemede, ilaç ve aşı çalışmalarında yapay zeka kullanımı, salgın yönetimi üzerinde önemli etkiler sunabilir.

Google, Türkiye için 5 Nisan 2020 tarihinde çok basit bir yapay zeka uygulamasıyla elde ettiği COVID-19 Topluluk Hareketliliği Raporunu yayınlamıştır ${ }^{25}$. Bu raporda salgın önlemleri doğrultusunda toplu taşıma duraklarında hareketliliğin salgın öncesine göre $\% 75$, parklarda $\% 60$, iş yerlerinde $\% 50$ ve marketlerde $\% 40$ azaldığı saptanmıştır. Bu tür bir sistemin ülke çapında geliştirilerek salgın döneminde sosyal mesafe önlemlerine ne kadar uyulduğunun takip edilmesi mümkün olabilecektir.

Çin'de mevcut COVID-19 salgını döneminde çok daha ayrıntılı yapay zeka uygulamaları geliştirilerek bireylerin hareketlerini, temaslarını, hastalık risklerini takip eden sistemler kullanıldığı bilinmektedir ${ }^{26}$. Projede bireylere, büyük veriye ve mobil internet teknolojilerine dayanarak yeşil, sarı ve kırmızı sağlık kodları verilmiştir. Renkler sağlık durumlarının yanı sıra seyahat geçmişi ve salgın bölgelerinde insanlarla temasa geçip geçmediklerini temsil ederken elde edilen bulgular sonucu kırmızı veya sarı kodlu olanların 14 gün karantinaya alınması sağlanmıştır.

Yakın zamanda geliştirilen bir başka uygulama olan COVID-19 Açık Araştırma Veri Kümesi (CORD-19), koronavirüs araştırmaları hakkındaki bilimsel makaleleri barındırmakta olup veri madenciliği ve bilgi alma sistemlerinin geliştirilmesini kolaylaştırmak için tasarlanmıştır ${ }^{27}$. Uygulama bilim insanlarının bilimsel veriye hızlı bir şekilde ulaşmalarına yardımcı olmaktadır. Bunun yanı sıra Dünya Sağlık Örgütü de COVID-19'la ilgili bilgilerin 2 milyardan fazla kişiye ulaşmasını sağlayan, Whatsapp ve Facebook üzerinden yapay zeka ile geliştirilmiş bir bilgi alma sistemini yayına almıştır ${ }^{28}$.

Virüsün teşhisi için makine öğrenimine dayalı çeşitli yöntemler üzerine çalışmalar mevcuttur. Gozes ve ark. virüsün tespiti ve takibi için toraks $\mathrm{BT}$ görüntüleri üzerinden yapay zeka tabanlı otomatik görüntü analizi yapan bir araç geliştirmiş ve uygulamanın oldukça yüksek başarı oranına sahip olduğunu bildirmiştir ${ }^{29}$. Wang ve ark. kamera görüntüleri üzerinden kişilerin solunum paternlerinin belirlenmesi ve tespit edilen paternlerle hastalık tanısına yardımcı olmak üzere derin öğrenme tabanlı kapsamlı araçlar geliştirmekte$\operatorname{dir}^{30}$. Geliştirilen araçların büyük ölçekli olarak COVID-19 tespitinde kullanılabilmesi de hedeflenmektedir. Gerçek zamanlı verilerin elde edilmesi, yapay zeka çalışmaları için son derece önemli olduğu gibi aynı zamanda bu verilerin sağlanması oldukça güçtür ${ }^{31}$. Dünya çapında hasta verilerinin birleştirilmesi ve erişilebilir veri tabanlarının oluşturulması, mevcut pandeminin yanı sıra gelecekteki salgınlar için de güçlü bir katkı sağlayacaktır.

\section{Bulaşıcı Olmayan Hastalıklar}

Bilgi sistemlerinin coğrafi olarak uyarlanması salgın hastalıkların yanı sıra çevresel ve mesleki hastalıkların tespiti ve takibi, hava kalitesinin izlenmesi ve öngörülmesi gibi konularda da fayda sağlama potansiyeline sahiptir $^{32}$. Sosyal medya üzerinden salgın hastalık takiplerinin yanı sıra obezite, diyabet, fiziksel aktivite sıklığı, alkol veya sigara kullanımı gibi yaşam tarzına bağlı özelliklerin de takibi mümkündür. Garimella ve ark. Instagram uygulaması üzerinden coğrafi olarak etiketlenmiş fotoğrafları ve açıklamalarını analiz ederek ilçe düzeyinde sağlık istatistiklerinin tahmin edilebileceğini göstermiştir ${ }^{33}$. Paul ve ark. salgında kullanılanlara benzer modellerle insanların Twitter üzerinden yazdıkları mesajlarda alerji, obezite ve uykusuzluk dahil birçok hastalığ 1 araştırmışlardır ${ }^{34}$. Yine sosyal medya mesajları üzerinden intihar düşüncesi olanların tespit edilmesi ve sağlık kuruluşlarına yönlendirilmesi mümkündür ${ }^{35}$. Elde edilen sonuçlar, özellikle Twitter'ın Halk Sağlığı araştırmaları için geniş uygulanabilirliğe sahip olduğunu göstermektedir.

Fransa'da yapılan bir çalışmada meme taraması yaptırma oranlarının şehirler arasında, hatta aynı şehrin farklı bölgeleri arasında ciddi farklarının olduğu görülmüştür ${ }^{8}$. Yapay zeka uygulamaları, bu popülasyonları sürekli gözleyip tarama oranlarını takip ederek tarama katılımını iyileştirme konusunda yardımcı olabilir. Bireylerin sağlıkları ortak bir sistemde takip edilerek, hastalıkların bireysel tanımlamalarına kadar inilebilir. Akıllı telefonların yanı sıra giyilebilir, implante edilebilir ve ortam sensörleri gibi teknolojiler sağlığın sürekli olarak izlenmesini sağlamada yardımc1 olabilir ${ }^{36}$. Örneğin, gün boyunca gıda alımı ve enerji harcamalarının doğru bir şekilde tahmin edilmesi, obezite ile başa çıkmada katkı sağlayabilir. Çeşitli hastalıklar için mobil uygulamalar üzerinden -saat çizimi ile Alzheimer tanısı örneğinde olduğu gibi- çok düşük maliyetlerle toplum taraması yapmak mümkün olabilir. Kronik hastalıkları olan yaşlı bireyler için, kendi evlerinde bağımsız şekilde yaşamaya devam etmelerini sağlayarak bakım kalitesini artırmak için kullanılabilir. Hastaların vital bulguları sürekli takip edilerek, bozulmalar yaşandığında uyarı verilmesi, ciddi durumlarda acil sağlık hizmetlerine haber verilmesi sağlanabilir. Yetiyitimli hastaların ve rehabilitasyon gören bireylerin bakımına katkı verilebilir. Poggi 


\section{Halk Sağlığında Yapay Zeka}

ve ark. tarafından geliştirilen, görme bozukluğu olan hastalar için tasarlanmış olan engel takip sistemi bu konuda örnek gösterilebilecek önemli bir çalışmadır ${ }^{37}$. Uygulamada görme engelli hastaların navigasyon yardımıyla gitmek istedikleri yere yönlendirilmesi, bu sırada çevredeki engellere karşı sensörlerle denetim yapılarak gerekli durumlarda sesli uyarı verilmesi amaçlanmaktadır.

Yapay zeka ile hastalıklardan korunma, tarama ve sonrasında tedavi aşamasında bireyselleştirilmiş planlar sayesinde hastalıkların önlenmesi, erken teşhis ve tedavi süreci gibi bir çok alanda avantaj sağlanabilir ${ }^{15}$. ABD'de internet üzerinden yapılan aramalarla pankreatik adenokarsinoma erken tanı koymanın mümkün olabileceğine yönelik bir çalışma yapılmıştır ${ }^{38}$. Bu çalışmada tanı almış kişilerin internet arama geçmişleri incelenerek ilgili semptomlara yönelik aramalar belirlenmiş ve bu bilgilere dayanarak bir model oluşturulmuştur. Model sayesinde vakaların \%5 ila 15'inin tespit edilebileceği gösterilmiştir. $\mathrm{Bu}$ oran düşük görünse de pankreatik adenokarsinom gibi 1 yıldan daha kısa bir sürede evre 1'den evre 4'e ilerleyebilen bir hastalığın erken teşhisine katkı sağlamada önemli bir yöntem olabilir.

Geleceğe yönelik olarak yapay zekanın uygulama olanakları ve özellikle büyük verinin potansiyeli oldukça fazladır. Küresel çapta kurulacak sağlık sistemlerinin epidemiyolojik faydalarının yanı sıra, özellikle pandemi gibi küresel acil durumlarda, anlık bilgiyi milyonlarca hekime ulaştırmak gibi zorlu bir iş yerine, bir saniyeden k1sa bir sürede tüm sistemlerde bu bilgiyi güncellemek mümkün olacaktır. Öte yandan yapay zeka uygulamalarının mümkün olduğunca küçük ölçeklerde uygulanması gerektiğini, genellemelerin hatalara yol açabileceğini belirten görüşler de mevcuttur $^{39}$.

İngiltere'de 2019 yılında 250 milyon sterlin yatırımla bir ulusal yapay zeka laboratuvarı kurulacağı açıklanmıştır ${ }^{40}$. Bu yatırımla radyolojik görüntülerle hastalık bulgularını saptamadan gelecekteki hastane yatışlarını tahmin etmeye kadar birçok alanda teknoloji geliştirilmesi hedeflenmektedir. Ülkemizde de Sağlık Bakanlığına bağlı Sağlık Bilgi Sistemleri Genel Müdürlüğünün Proje Geliştirme Dairesi Başkanlığında bir Yapay Zeka Birimi mevcuttur. Bu birimin "büyük veri uygulamaları için gerekli altyapıyı kurmak", "yapay zeka uygulamalarının sağlık alanında geliştirilmesine yönelik güçlü iş birlikleri oluşturmak" gibi amaçları tanımlanmıştır ${ }^{41}$. 2019 yılının sonunda Türkiye Sağlık Enstitüleri Başkanlığına bağlı Sağlık Veri Araştırmaları ve Yapay Zeka Uygulamaları Enstitüsünün kurulduğu duyurulmuştur ${ }^{42}$.

\section{Potansiyel Sorunlar}

Yapay zekanın modern tıbba entegre edilmesinin bazı potansiyel olumsuz sonuçları mevcuttur. Her ne kadar bilgisayarların işlem kapasiteleri insan zihninin milyarlarca kat üstüne çıkmış olsa da bilgisayarların öğrenmesi insan öğrenmesine göre çok daha zorlu bir süreçtir. Makineler insanda var olan soyutlama yeteneğine sahip değildir. İnsanın farkında bile olmadan sahip olduğu yeteneklerin makineye tek tek tanıtılması gerekmektedir.

Yapay zekaya olan büyük ilgiye ve verilerin Halk Sağlığında daha iyi kullanılmasının önemine işaret eden birçok düşünceye rağmen, heterojen verilerin entegrasyonunun karmaşıklığı ve sağlam ve tarafsız doğrulama prosedürlerinin eksikliği de dahil olmak üzere çeşitli potansiyel sorunlar bulunmaktadır ${ }^{43}$. Veri sistemleriyle ilgili öncelikli amaç, sistemlerin homojenleştirilmesi yönünde olmalıdır. Bunun dışında çeşitli etik ve hukuki problemler gündeme gelmektedir.

Büyük veri sistemlerinin güvenliğinin sağlanması, hasta gizliliğinin korunması önemli ve zorlayıcı konulardır. Özellikle kişisel bilgilerin yanı sıra konum ve sağlık bilgisinin de paylaşılması gizlilik ve veri güvenliği endişelerini artırmaktadır ${ }^{44}$. Veriler ne amaçla kullanılacaktır? Veri tabanlarına kimler erişim sağlayabilecektir? Kişisel verilerin ötesinde temel sağlık verileri bile kötüye kullanılabilir ve özellikle risk altındaki gruplarda ayrımcılığa yol açabilir ${ }^{45}$. Örneğin sigorta şirketleri bu verilere dayanarak vatandaşların başvurularını reddedebilir. İlaç şirketleri sisteme erişim sağlayarak belirli coğrafi bölgelerde ilaç fiyatlarını artırabilir'. 2019'un Ekim ayında Dünya Sağlık Örgütü, küresel sağlıkta yapay zekanın tasarımı ve uygulanması için etik ve yönetsel rehberliğinin geliştirilmesini sağlamak üzere uluslararası bir toplantı gerçekleştirmiştir. Dünya Sağlık Örgütü bu teknolojilerin uluslararası nitelikte olduğuna, ulusal sınırları tanımayacağına, dolayısıyla üretilen veya kullanılan verilerin erişimi ve paylaşılmasıyla ilgili oluşabilecek güvenlik sorunlarına dikkat çekmektedir ${ }^{46}$.

Bir yapay zeka modeline sağlık sistemlerini emanet etmenin doğasında kaçınılmaz olarak sosyal ve etik endişeler mevcuttur. Gelişen teknolojilerin ortaya koyduğu yeni yaklaşımlar beraberinde yeni soruları da getirmektedir. Tamamen teknolojiye bırakılmış bir karar verme sisteminde hata oluştuğunda sorumlu kim olacaktır? Sistem çalışmadığında yeri doldurulabilecek midir? Algoritmalar, uzmanın anlayamadığı "derin öğrenme" ile bir karar önerirse ne yapılmalıdır? Potansiyel olumsuz sonuçları olan müdahaleler önerilse bile, öneriye uyulmalı mıdır? Bu sorular göz önünde bulundurulmalı, karar verme süreçleri tamamen teknolojiye bırakılmamalıdır. Yapay zeka uygulamalarının süreci destekleyici biçimde kurgulanması önemlidir. 
Amerika Birleşik Devletleri'nde bir araştırma enstitüsü yayınladığı raporda yapay zeka uygulamalarının şeffaf olmadığına dikkat çekmiştir ${ }^{47}$. Bireylerin bu tür uygulama sistemlerinin nasıl karar verdiklerini bilmeleri gerektiği vurgulanmıştır. Bu doğrultuda derin öğrenme teknikleri daha anlaşılır hale getirilmeli ve kullanıcılarına ihtiyaç halinde hesap verebilme şansına sahip olmalıdır.

Sağlıkta meydana gelen teknolojik gelişmelerin sağlık alanındaki eşitsizlikleri ne yönde etkileyeceği de göz önünde bulundurulması gereken önemli bir konudur ${ }^{48}$. UNESCO’ya bağlı Uluslararası Biyoetik Komitesi (IRC) 2017 yılındaki raporunda dijital eşitsizliklerin giderilmesi ve bilgi ve iletişimin demokratikleştirilmesi gerektiğine, gelişen teknolojilerin herkes için erişilebilir olması gerektiğine dikkat çekmiştir ${ }^{49}$. Aynı zamanda yapay zeka sistemleri bu potansiyel soruna çözüm olabilecek şekilde en çok risk altında olan bireyleri ortaya çıkararak sağlık eşitsizliklerini azaltma yönünde de yardımcı olabilir ${ }^{39}$.

Bir başka endişe ise yapay zeka teknolojilerinin veriye dönüştürülebilen sorunlara odaklanmasıyla klinik olarak "gerçek" dünyada değerlendirilmesi gereken ve veriye dönüşemeyen sorunların gölgede kalabileceği yönündedir. Yapay zekanın nasıl fayda sağlayabileceğine dair bir yönlendirme ve kanıt eksikliği mevcuttur $^{50}$. Belki de öncelikle veri ve algoritmalara odaklanmak yerine, araştırmacılar toplum ve hekimlerle birlikte önemli kullanım durumlarının, fayda sağlayabilecek alanların tanımlanmasını sağlamak için çabalamalıdır. Yapay zekaya neden ihtiyaç duyulduğu veya yapay zekanın bireylerin sağlıklarının geliştirilmesini nasıl destekleyebileceği konusunda net bir anlayış oluşmadan, anlamlı ve sürdürülebilir bir etki yaratabilecek uygulamaları hayal etmek güçtür. Makine ve teknolojilerin amaç değil amaca yönelik birer araç olduğu unutulmamalıdır.

\section{Sonuç ve Öneriler}

Yapay zekaya ilişkin son dönemdeki gelişmeler tüm alanlarda olduğu gibi Halk Sağlığında da umut ve heyecan vericidir. Yapay zeka alanında birçok sektörde yaşanan gelişmeleri sağlık sektörünün de takip etmesi kaçınılmazdır. Yine de insan sağlığı gibi hata yapmanın kabul edilemeyeceği bir konuda diğer sektörlerde olduğu kadar hızlı ilerlemesi beklenmemelidir. Teknolojiden en iyi şekilde yararlanmak için sabırlı davranılmalı ve temkinli hareket edilmelidir. Geliştirilen uygulamalar uygun bilimsel çalışmalarla değerlendirilmeli, kanıta dayalı biçimde akılcı bir çerçevede ilerlenmelidir.

Halk Sağlığı alanında işlenmeyi bekleyen oldukça büyük veriler mevcuttur. İstatistikte ve teknolojide yaşanan gelişmelerin veri sistemlerine entegre edilmesi, sağlığın geliştirilmesi açısından önemli katkılar sunacaktır. Bulaşıcı hastalıkların yönetiminin yanı sıra özellikle çevresel ve mesleki hastalıklar başta olmak üzere kronik hastalıkların önlenmesinden sağlık ekonomisine kadar birçok konuda fayda sağlama potansiyeli bulunmaktadır.

Öte yandan hekimliğin doğası gereği sağlık hizmetleri tamamen teknolojiye terk edilmemelidir. Özellikle karar verme aşamasında hekim her zaman kontrole sahip olmalıdır. Daima istenmeyen sonuçlara karşı duyarlı olan temkinli bir tutumla hareket edilmelidir. Bunun yanı sıra hekimler de yeni gelişmelere karşı ön yarg1lı olmamalı, sürece dahil olarak en iyi sonucun oluşmasına katkı sağlamalıdır.

Yapay zekanın kısa ve uzun vadeli etkilerini değerlendirebilecek kurumlara ve nitelikli personele ihtiyaç duyulmaktadır. Geliştiriciler, uygun teknolojilerin benimsenmesinin yanı sıra güvenliğin değerlendirilmesi ve izlenmesi ile hesap verebilirlik ve şeffaflık mekanizmalarını da göz önünde bulundurmalıdır. Gelişen teknolojilerin sağlıkta eşitsizlikleri artırmamas1, toplumun tüm kesimlerinin bu hizmetlerden yararlanabilmesi amaçlanmalıdır. Bilimsel gelişmelerde olduğu gibi teknolojik gelişmeler de sağlığın geliştirilmesi yolunda kullanılmalıdır.

\section{Araştırmacı Katkı Beyanı:}

Fikir ve tasarım: M.Ç., H.E.A.; Makalenin önemli bölümlerinin yazılması: H.E.A.

\section{Destek ve Teșekkür Beyanı:}

Makale için finansal destek alınmamıştır. Çalışmaya dışardan yardımcı olan bir kişi yoktur.

\section{Çıkar Çatışması Beyanı:}

Makale yazarlarının çıkar çatışması beyanı yoktur.

\section{Kaynaklar}

1. Topol EJ. High-performance medicine: the convergence of human and artificial intelligence. Nat Med. 2019;25(1):44-56.

2. Türk Dil Kurumu. Güncel Türkçe Sözlük. [Erişim Tarihi: 29 Haziran 2020]. Erişim: https://sozluk.gov.tr/

3. Russell SJ, Norvig P. Artificial Intelligence: A Modern Approach. 3. baskı. New Jersey: Prentice Hall; 2009.

4. Bishop C. Pattern Recognition and Machine Learning. Jordan M, Kleinberg J, Scholkopf B, editörler. New York: SpringerVerlag; 2006.

5. Schmidhuber J. Deep learning in neural networks: An overview. Neural Networks. 2015;61:85-117.

6. Houssami N, Lee CI, Buist DSM, Tao D. Artificial intelligence for breast cancer screening: Opportunity or hype? Breast. Aralık 2017;36:31-3.

7. Kantarjian H, Yu PP. Artificial Intelligence, Big Data, and Cancer. JAMA Oncol. Ağustos 2015;1(5):573-4.

8. Thomassin-Naggara I, Balleyguier C, Ceugnart L, Heid P, Lenczner G, Maire A, vd. Artificial intelligence and breast screening: French Radiology Community position paper. Diagn Interv Imaging. Ekim 2019;100(10):553-66.

9. Egger K, Strecker C, Kellner E, Urbach H. Otomatik analiz algoritmaları kullanarak akut iskemik inmede görüntüleme. 


\section{Halk Sağlığında Yapay Zeka}

Nervenarzt. 2018;89(8):885-94.

10. Bhattacharya S, Pradhan KB, Bashar MA, Tripathi S, Semwal J, Marzo RR, vd. Artificial intelligence enabled healthcare: A hype, hope or harm. J Fam Med Prim care. 15 Kasim 2019;8(11):3461-4.

11. Khorrami M, Prasanna P, Gupta A, Patil P, Velu PD, Thawani $\mathrm{R}$, vd. Changes in CT Radiomic Features Associated with Lymphocyte Distribution Predict Overall Survival and Response to Immunotherapy in Non-Small Cell Lung Cancer. Cancer Immunol Res. 2020;8(1):108-19.

12. Tutun S, Irgil S, Yeşilkaya I, Aykaç A, Aras N. WeCureX Intelligent Psychiatric Assistant. Informs 2018 Annual Meeting. Phoenix; 2018.

13. Binaco R, Calzaretto N, Epifano J, McGuire S, Umer M, Emrani S, vd. Machine Learning Analysis of Digital Clock Drawing Test Performance for Differential Classification of Mild Cognitive Impairment Subtypes Versus Alzheimer's Disease. J Int Neuropsychol Soc. 2020/03/23. 2020;1-11.

14. Haenssle HA, Fink C, Schneiderbauer R, Toberer F, Buhl T, Blum A, vd. Man against machine: diagnostic performance of a deep learning convolutional neural network for dermoscopic melanoma recognition in comparison to 58 dermatologists. Ann Oncol Off J Eur Soc Med Oncol. Ağustos 2018;29(8):1836-42.

15. Schneider F, Weiller C. Big Data and Artificial Intelligence. Nervenarzt. 2018;89(8):859-60.

16. Türkiye Teknoloji Geliştirme Vakfı. Sağlık ve Dijitalleşme. Teknoloji Dosyası 1. Ankara; 2017.

17. Miotto R, Li L, Kidd BA, Dudley JT. Deep Patient: An Unsupervised Representation to Predict the Future of Patients from the Electronic Health Records. Sci Rep. 2016;6(1):26094.

18. Liu B, He H, Luo H, Zhang T, Jiang J. Artificial intelligence and big data facilitated targeted drug discovery. Stroke Vasc Neurol. 2019;4(4):206-13.

19. Wakefield J. Artificial intelligence-created medicine to be used on humans for first time. 2020 [Erișim Tarihi: 27 Haziran 2020]. Erişim: https://www.bbc.com/news/technology-51315462

20. Gönel A, Bayraktar N, Koyuncu İ. Yapay Zeka Programı ile Gereksiz Laboratuvar Testlerinin Engellenmesi (Sözel Bildiri). Uluslararası Sağlıkta Yapay Zeka Kongresi. İzmir; 2020.

21. Lu FS, Hattab MW, Clemente CL, Biggerstaff M, Santillana M. Improved state-level influenza nowcasting in the United States leveraging Internet-based data and network approaches. Nat Commun. 2019;10(1):147

22. Yousefinaghani S, Dara R, Poljak Z, Bernardo TM, Sharif S. The Assessment of Twitter's Potential for Outbreak Detection: Avian Influenza Case Study. Sci Rep. 2019;9(1):18147.

23. González C, Wang O, Strutz SE, González-Salazar C, SánchezCordero V, Sarkar S. Climate change and risk of leishmaniasis in north america: predictions from ecological niche models of vector and reservoir species. PLoS Negl Trop Dis. 19 Ocak 2010;4(1):e585-e585.

24. Vaishya R, Javaid M, Khan IH, Haleem A. Artificia Intelligence (AI) applications for COVID-19 pandemic. Diabetes Metab Syndr. 2020;14(4):337-9.

25. Topluluğunuzun COVID-19 nedeniyle nasıl farklı hareket ettiğini görün. 2020 [Erişim Tarihi: 06 Haziran 2020]. Erişim: https://www.google.com/covid19/mobility/

26. Pan X-B. Application of personal-oriented digital technology in preventing transmission of COVID-19, China. Ir J Med Sci. 27 Mart 2020;1-2.

27. Lu Wang L, Lo K, Chandrasekhar Y, Reas R, Yang J, Eide D, vd. CORD-19: The Covid-19 Open Research Dataset. ArXiv. 2020.

28. World Health Organization. WHO Health Alert brings COVID19 facts to billions via WhatsApp. 06.05.2020. [Erişim Tarihi: 28 Haziran 2020]. Erişim: https://www.who.int/newsroom/feature-stories/detail/who-health-alert-brings-covid-19-

\section{facts-to-billions-via-whatsapp}

29. Gozes O, Frid-Adar M, Greenspan H, Browning PD, Zhang H, Ji W, vd. Rapid ai development cycle for the coronavirus (covid-19) pandemic: Initial results for automated detection \& patient monitoring using deep learning ct image analysis. arXiv Prepr arXiv200305037. 2020;

30. Wang Y, Hu M, Zhou Y, Li Q, Yao N, Zhai G, vd. Unobtrusive and Automatic Classification of Multiple People's Abnormal Respiratory Patterns in Real Time Using Deep Neural Network and Depth Camera. IEEE Internet Things J. 2020;7(9):8559-71.

31. Alimadadi A, Aryal S, Manandhar I, Munroe PB, Joe B, Cheng $\mathrm{X}$. Artificial intelligence and machine learning to fight COVID19. Physiol Genomics. 2020/03/27. 01 Nisan 2020;52(4):200-2.

32. Özçelik AE. Çevre Ve Meslek Hastalıkları İçin Akıllı Coğrafi Bilgi Sistemi (Sözel Bildiri). Uluslararası Sağlıkta Yapay Zeka Kongresi. İzmir; 2020.

33. Garimella V, Alfayad A, Weber I. Social Media Image Analysis for Public Health. 2016. 5543-5547 s.

34. Paul M, Dredze M. You Are What Your Tweet: Analyzing Twitter for Public Health. Artif Intell. 01 Ocak 2011;38:265-72.

35. Graham S, Depp C, Lee EE, Nebeker C, Tu X, Kim H-C, vd. Artificial Intelligence for Mental Health and Mental Illnesses: an Overview. Curr Psychiatry Rep. Kasım 2019;21(11):116.

36. Ravì D, Wong C, Deligianni F, Berthelot M, Andreu-Perez J, Lo B, vd. Deep Learning for Health Informatics. IEEE J Biomed Heal Informatics. 2017;21(1):4-21.

37. Poggi M, Mattoccia S. A wearable mobility aid for the visually impaired based on embedded 3D vision and deep learning. Içinde: 2016 IEEE Symposium on Computers and Communication (ISCC). 2016. s. 208-13.

38. Paparrizos J, White RW, Horvitz E. Screening for Pancreatic Adenocarcinoma Using Signals From Web Search Logs: Feasibility Study and Results. J Oncol Pract. Ağustos 2016;12(8):737-44.

39. Liyanage $H$, Liaw S-T, Jonnagaddala J, Schreiber R, Kuziemsky C, Terry AL, vd. Artificial Intelligence in Primary Health Care: Perceptions, Issues, and Challenges. Yearb Med Inform. Ağustos 2019;28(1):41-6.

40. O’Dowd A. Government pins hopes on £250m AI centre for faster diagnosis and treatment. BMJ. 09 Ağustos 2019;366:15106.

41. Sağlık Bakanlığı. Proje Geliştirme Dairesi Başkanlığı Görev ve Sorumlulukları. 2020 [Erişim Tarihi: 28 Haziran 2020]. Erişim: https://sbsgm.saglik.gov.tr/TR,12828/proje-gelistirme-dairesibaskanligi.html

42. Karaaslan YS, Yener D. Sağlık Bakanlığından "Yapay Zeka Enstitüsü”. 23.12.2019. [Erişim Tarihi: 27 Haziran 2020]. Erişim: https://www.aa.com.tr/tr/saglik/saglik-bakanligindanyapay-zeka-enstitusu/1681402

43. Rodríguez-González A, Zanin M, Menasalvas-Ruiz E. Public Health and Epidemiology Informatics: Can Artificial Intelligence Help Future Global Challenges? An Overview of Antimicrobial Resistance and Impact of Climate Change in Disease Epidemiology. Yearb Med Inform. Ağustos 2019;28(1):224-31.

44. Eskiocak M. Koronavirüs Pandemisi, Salgın Yönetimi, Dijital İzleme ve Endişe. Hekim Postası Haziran 2020 Korona Pandemisi Özel. [Erişim Tarihi: 28 Haziran 2020]. Erişim: https://ato.org.tr/hekim_postasi_arsiv/2020/hp_pandemi_ozel2. pdf

45. Vayena E, Dzenowagis J, Brownstein JS, Sheikh A. Policy implications of big data in the health sector. 2017 [Erişim Tarihi: 28 Haziran 2020]. Erişim: https://www.who.int/bulletin/volumes/96/1/17-197426/en/

46. World Health Organization. Big data and artificial intelligence. [Erişim Tarihi: 28 Haziran 2020]. Erișim: https:/www.who.int/ethics/topics/big-data-artificial- 


\section{H.E. Alıcılar ve M. Çöl}

\section{intelligence/en/}

47. Campolo A, Sanfilippo M, Whittaker M, Crawford K. AI Now 2017 Report. Selbst A, Barocas S, editörler. New York; 2017.

48. Şemin S. Tıbbi teknoloji, hekimler ve etik. Içinde: Sağlık Hizmetlerinde Teknoloji. Ankara: Türk Tabipleri Birliği; 1999. s. 45.
49. International Bioethics Committee. Report of the IBC on big data and health. Paris; 2017.

50. Lau AYS, Staccini P. Artificial Intelligence in Health: New Opportunities, Challenges, and Practical Implications. Yearb Med Inform. Ağustos 2019;28(1):174-8. 